\title{
ЦИФРОВОЙ ЭТАП В РАЗВИТИИ ЭКОНОМИКИ
}

\section{М. П. Сташевская ${ }^{1}$}

${ }^{1}$ Магистр экономических наук, старший преподаватель кафедры «Экономика и право» учреждения образования «Белорусский национальный технический университет», Минск, Беларусь, e-mail: m.stasheuskaya@gmail.com

\section{Реферат}

Отправной точкой выделения цифровой экономики служит переход к новому витку технологического развития. Условиями формирования цифровой экономики согласно системе периодизации эволюции техники и технологий на основе выделения промышленных (индустриальных) революций служит четвертая индустриальная революция, согласно системе периодизации технико-технологического прогресса С. Глазьева шестой технологический уклад.

Определение особенностей, закономерностей и отличительных черт цифрового этапа экономического развития необходимо для последующего выведения принципов развития в новых условиях и поиска оптимальных сценариев экономического планирования. В статье предлагается рассмотрение нескольких точек зрения, отражающих основные черты и особенности цифровой экономики.

Ключевые слова: цифровая экономика, цифровые технологии, данные, информация, знания, информационно-коммуникационные технологии, цифровизация.

\section{DIGITAL STAGE IN ECONOMY DEVELOPMENT}

\section{Abstract}

\section{P. Stashevskaya}

The starting point for distinguishing the digital economy is the transition to a new round of technological development. The conditions for the formation of a digital economy according to the system of periodization of the evolution of technology and technology based on the separation of industrial revolutions are the fourth industrial revolution, according to the system of periodization of technical and technological progress by S. Glazyev - the sixth technological order.

Determination of the features, patterns and distinctive features of the digital stage of economic development is necessary for the subsequent derivation of the principles of development in new conditions and the search for optimal scenarios of economic planning. The article proposes to consider several points of view, reflecting the main features and characteristics of the digital economy.

Keywords: digital economy, digital technologies, data, information, knowledge, information and communication technologies, digitalization.

\section{Введение}

Активное использование информационных технологий приводит к изменениям в общественно-экономических и хозяйственных отношениях, их цифровизации. Взаимодействие в таких отношениях основывается на использовании цифровых данных. Объем цифровой экономики поступательно увеличивается, как утверждают в своем исследовании Р. Бухт и Р. Хикс, и по состоянию на 2018 г. составляет примерно $5 \%$ мирового ВВП [1, с. 155]. Одно из ключевых явлений, влияющих на выделение цифровой экономики, заключается в увеличении роли видов деятельности, которые формируют цифровые продукты. Понятие «цифровая экономика» является достаточно новым и требует теоретического всестороннего осмысления, выяснение сущности и природы явлений цифровизации экономической деятельности.

\section{Развитие экономики в период цифровизации}

В качестве основы выделения цифровой экономики определяется новая технологическая база, сформированная на основании цифровых технологий, при этом часть авторов сконцентрирована на исследовании влияния этих технологий на воспроизводственный процесс, часть - на особенностях макроэкономических изменений, часть на роли человека в такой экономике. В результате исследований перечисленных авторов сложилось несколько подходов к определению цифровой экономики: воспроизводственно-цифровой (Г. Б. Клейнер [2] А. Н. Козырев [3], В. В. Великороссов, С. А. Филин, О. Н. Калинина [4] Р. Бухт, Р. Хикс [1]), макро-ориентированный (Л. Сергеев [5]), человеко-детерминированный (Т. Н. Юдина, И. 3. Гелисханов [6], Ю. В. Белоусов, И. И. Тимофеева [7], В. В. Иванов, Г. Г. Малинецкий [8]).

Г. Б. Клейнер под цифровой экономикой предлагает понимать «состояние (этап развития) экономики, при котором: а) процессь производства, распределения, обмена и потребления, включая все связанные с ними коммуникации и взаимодействия, осуществляются на основе цифровых технологий; б) реальные экономические процессы, объекты, проекты, среды в ходе коммуникации и взаимодействия дополняются, а порой и заменяются их компьютерными (цифрровыми) моделями» [2, с. 21]. Сближение процессов производства, распределения, обмена и потребления, реализуемых за счет технологий «большие данные», блокчейн, искусственного интеллекта, цифровых двойников, сопровождается усилением влияния таких технологий на конечный результат. Технология «большие данные» называется этим автором в числе цифровых технологий, которые применяются для ответов на вопросы «что производить» и «кому продавать». [2, с. 24]. В качестве основных предметов коммуникационно-управленческих процессов в развитой цифровой экономике называются данные, информация, знания и модели [2, с. 22].

Интеграция баз данных и баз знаний, состоящих из данных о поведении индивидов, товаров, агентов и систем, позволит «к концу цифрового века расширится до маршрутизации всех видов взаимодействия человека с окружающей социально-экономической и природно-технической средой» [2, с. 30]. Взгляды Г. Б. Клейнера позволяют выявить информационно-технологическую основу функционирования воспроизводственного механизма в цифровой экономике, характеризующегося сближением производства, распределения, обмена, потребления. Обработка постоянно пополняемых данных становится одним из ключевых элементов развития воспроизводства за счет, во-первых, точного прогнозирования его объемов и структуры, во-вторых, влияния на процесс принятие решения человеком. Базы данных, знаний и предпочтений совместно с развитием методологии и методики компьютерного социально-экономического моделирования, с одной стороны, могут привести к транспарентности и управляемости отношений, с другой - могут стать источником вытеснения человека или групп людей из определенных сфер, лишая человека возможности самостоятельного принятия решения.

Рассматривая цифровую экономику как сектор реальной экономики и как научное направление, А. Н. Козырев подчеркивает, что в обоих 
Вестник Брестского государственного технического университета. 2021

направлениях «речь идет о цифровизации, о свойствах информации в цифровом формате и ее роли в экономике» [3, с. 5]. Для понимания реального сектора экономики А. Н. Козырев полагает возможным использование официального определения: «хозяйственная деятельность, в которой ключевым фактором производства являются данные в цифровом виде, обработка больших объемов и использование результатов анализа которых по сравнению с традиционными формами хозяйствования позволяют существенно повысить эффективность различных видов производства, технологий, оборудования, хранения, продажи, доставки товаров и услуг» [3, с. 6]. При описании цифровой экономики как научного направления названный автор подчеркивает, что в таком направлении используются математические модели экономики, прежде всего, «с учетом фундаментальных свойств информации и знаний, как правило, представленных в цифровом формате» [3, с. 7].

Цифровизация экономики, как отмечает А. Н. Козырев с опорой на работу Д. Тапскотта, проявляется в изменении трансакционных издержек, изменении роли посредников, развитии совместного использования благ и особенностях цифровой продукции. Изменение трансакционных издержек проявляется в сокращении таких их видов, как издержки, подобные «трению в экономике» - издержки поиска информации, измерений, ведения переговоров, тогда как издержки неисполнения обязательств и служебных обязанностей (оппортунистического поведения) возрастают в связи с расходами на борьбу с «пиратством» и ущербом от него [3, с. 10-11]. Деятельность посредников, называемая Д. Тапскоттом «усилением слабых сигналов», как пишет А. Н. Козырев, в цифровой экономике становится не нужной, «поскольку каждый может усиливать свой сигнал и различать довольно слабые сигналы» [3, с. 13]. Примерами таких процессов служит способность производителя самостоятельно устанавливать контакт с потребителем, потребителя - с производителем. Совместное использование благ в цифровой экономике реализуется за счет возможности совместного использования информации, примером чего выступает совместное использование баз данных, применение которых «одним агентом не мешает одновременному использованию того же знания другим агентом или агентами» [3, с. 14].

Основу хозяйственного механизма цифровой экономики составляет информация в цифровом формате, свойства которой определяют особенности цифровых продуктов (нематериальность, нерасходуемость, возможность одновременного использования, неконкурентность в потреблении, возможность передачи без потери точности) и товаров (редкость обеспечивается путем регулирования распространения). Полезность цифровых продуктов определяется их содержанием, переходящая в коммерческую ценность благодаря свойству редкости цифрровых товаров. В цифровой экономике меняется механизм поиска информации, измерений, ведения переговоров, в результате чего снижаются трансакционные издержки по таким видам деятельности, тогда как отдельные издержки, связанные с неисполнением обязательств, наоборот возрастают.

По мнению В. В. Великороссова, С. А. Филина и О. Н. Калининой, цифровая экономика, базой которой служат сетевые сервисы, формируется в результате совершенствования цифровых технологий, ускоряющих обмен инфрормацией [4, с. 707]. Вслед за А. Н. Козыревым, названные исследователи фиксируют, что цифровизация технологических процессов сокращает отдельные трансакционные издержки во многом решая организационно-управленческие и хозяйственные проблемы. В. В. Великороссов, С. А. Филин и О. Н. Калинина предлагают определять понятие «цифровая экономика» с учетом того, что «в него должны входить информационная составляющая, хозяйственная (производственная, организационно-управленческая и экономическая) деятельность общества и совокупность отношений, складывающихся в системе производства, распределения, обмена и потребления, а конечной целью должно стать обеспечение личного и общественного благосостояния» [4, с. 713]. Эти авторы предлагают определять цифровую экономику как глобальную систему экономических отношений, конкретизируя, что такие отношения складываются «в системе производства, распределения, обмена и потребления вследствие мобилизации возможностей ИКТ (информационно-коммуникационных технологий - примечание М. С.) в конечном счете на благо потребителей, бизнеса, общества и государства» [4, с. 713]. Функционирование данной системы обеспечивается благодаря производству цифрового оборудования, созданию мультимедийного пространства, программированию и цифровым ИКТ [4, с. 713-714]. Структура цифровой экономики, предложенная названными авторами, состоит из информационной, хозяйственной подсистем и подсистемы отношений, объединение которых происходит благодаря цифрровым ИКТ.

Определяя цифровую экономику как «часть общего объема производства, которая целиком или в основном произведена на базе цифровых технологий фирмами, бизнес-модель которых основывается на цифрровых продуктах или услугах» [1, с. 155], Р. Бухт, Р. Хикс подчеркивают одновременную расплывчатость и гибкость такого определения, позволяющую учитывать будущее развитие технологий. Зачастую сущность определения цифровой экономики зависит не только от конкретного исторического периода, но и соответствующего данному периоду перечня технологий. Примерами таких обобщений служат определения цифровой экономики, в которых в качестве основных технологий сначала использовались интернеттехнологии, после - мобильные и беспроводные сети, облачные технологии и технологии работы с «большими данными». Упомянутые авторы фиксируют неравномерность распространения цифровой экономики, ее влияние на рост занятости, а также более быстрый темп роста по сравнению с ростом экономики в целом, дополняя свои выводы данными исследования Всемирного экономического форума за 2015 г.: «"интернет-экономика" в странах “Группы двадцати" увеличивается на $10 \%$ в год, что значительно превышает темп роста экономики "Группы двадцати"» [1, с. 159]. Производство в цифровой экономике осуществляется на основе цифровых технологий, к которым упомянутыми авторами отнесены Интернеттехнологии, мобильные и беспроводные сети, облачные технологии и технологии работы с «большими данными».

Л. Сергеев обращает внимание на политико-экономический смысл цифровой экономики, фиксируя, что такая экономика есть «определенная специфическая область знаний политической экономии, которая фокусирует в себе как социальные, так и экономические стороны общественного развития, но уже на новых сетевых платформах и цифровых базах данных, которые качественно и количественно изменяют технологические процессы жизнедеятельности в обществе» [5, с. 47]. Природа такой экономики состоит в действии закона экономии общественно необходимых затрат труда и общественного времени, т. е. в сокращении затрат труда и времени на производство по мере развития общественных формаций. Цифровую экономику по сравнению с аналоговой характеризует ряд политэкономических признаков, которые приобретают ускоренный формат, происходит ускорение: воспроизводственных процессов; роста овеществленного труда в сравнении с динамикой живого труда за счет использования робототехники, искусственного интеллекта, сетевых платформ управления, облачных технологий; роста органического строения капитала; развития информационных технологий и сетевых платформ как факторов производства; роста знаний и навыков в сфере информационных технологий [5, с. 48-53]. Применение информационных баз данных, позволяющих формировать политику спроса и предложения онлайн, формирует ускоренное достижение рыночного равновесия.

По мнению упомянутого автора, за счет использования цифровых платформ и развития информационно-коммуникационных технологий действие закона потребления и накопления в цифровой экономике характеризуется ростом качества потребления, наблюдается повышение эфффективности общественного производства и уменьшение дисбаланса затрат и результатов в системах с причинно-следственными связями. Проявление действия закона стоимости заключается в том, что в обмене товаров учитывается снижение их стоимости за счет использования информационно-коммуникационных технологий, в результате происходит преобразование процесса обмена товаров на новой цифровой основе, которая получает новую составляющую процесса оценки общественно-необходимых затрат труда на рынке - цифровую [5, с. 48-53]. 
По поводу действия закона макроэкономического равновесия в цифровой экономике Л. Сергеев отмечает комплексность его проявления и отражение в росте влияния требований закона возвышения потребностей, планомерного развития народного хозяйства, пропорциональности производства и потребления. При этом уменьшается влияние закона стоимости, цикличности производства, теневой экономики и черного рынка [5, с. 52-53]. Л. Сергеев также уделяет внимание роли государства в цифровой экономике, отмечая, что происходит снижение степени централизации государственного управления при одновременном усилении межгосударственного регулирования социально-экономических процессов.

Исследование Л. Сергеева демонстрирует, что цифровая экономика, понимаемая как область знаний политической экономии, сосредоточена на изучении социально-экономических механизмов и изменений, которые основаны на информационных технологиях и сетевых платформах. Ключевые изменения воспроизводственного процесса проявляются, в первую очередь, в значительном его ускорении. В качестве факторов производства справедливо называются информационные технологии и сетевые платформы. «Цифровую» основу приобретают закон макроэкономического равновесия, в результате увеличивается влияние требований закона возвышения потребностей, планомерного развития народного хозяйства, пропорциональности производства и потребления.

Для понимания и определения феномена цифровой экономики Т. Н. Юдина и И. 3. Гелисханов обращаются к анализу имеющихся распространенных трактовок цифровой экономики (определения Аналитического центра при Правительстве Российской Федерации, Правительства Австралии, Правительства Великобритании, Всемирного банка, Организации экономического сотрудничества и развития, Оксфордского словаря). В качестве детерминирующих цифровую экономику факторов названными авторами в упомянутых источниках определений выделены цифровые информационно-коммуникационные технологии и Интернет. На основании проведенного анализа, Т. Н. Юдиной и И. 3. Гелисхановым цифровая экономика рассматривается как экономика нового технологического уклада, которая в широком смысле означает: «изменение природы и трансформацию производственных отношений, смену их субъектно-объектной ориентированности; возникновение отношений типа машина - машина (M2M, Machine-to-Machine - примечание М. С.) или система система (S2S, System-to-System - примечание M. C.), где человек может уже не выступать субъектом, превратившись в неоантропа, машину, биоробота, киборга <...> появление интернета-вещей (IOT, Internet of Things - примечание М. С.), интернета-всего, когда все объекты и субъекты объединены в сеть» [6, с. 173]. По поводу сущности цифровой экономики в философско-хозяйственном и политико-экономическом смыслах Т. Н. Юдина и И. З. Гелисханов пишут об изменении самого человека, происходящего благодаря синтезу и взаимодействию в физических, биологических и цифрровых доменах Такого рода анализ приводит упомянутых авторов к выводу, что цифровую экономику можно «позиционировать» как «последнюю стадию развития капитализма <...> интернетизирующийся и кибернетизирующийся организм, "подглядывающий капитализм"» $[6$, с. 173] Т. Н. Юдина, И. 3. Гелисханов, справедливо определяя цифровую экономику как экономику нового технологического уклада, фиксируют изменения природы и субъектно-объектной ориентированности производственных отношений. Смена субъектной роли человека происходит за счет масштабного развития технологий, в том числе формирования отношений типа машина-машина и сетевого механизма взаимодействия.

Ю. В. Белоусов и И. И. Тимосреева, «рассматривая множество десиниций цифровой экономики», выделяют два методологических подхода: первый «состоит в том, что цифровой экономикой признается та или иная часть экономики», второй «заключается в признании цифровой экономики особым видом экономики в целом, безотносительно к отраслевой принадлежности, при этом определение экономики как цифровой иногда рассматривается как новый этап развития экономики» [7, с. 80-81]. Упомянутые авторы также пишут, что «довольно широкое распространение получило еще одно определение», в котором «цифровой называется экономика, основанная на цифровых технологиях» [7, с. 81]. Подчеркивая, что «классификация экономики по критерию варианта воздействия субъекта производственной деятельности на предметы и средства труда является одним из множества способов классификации экономики» [7, с. 85], эти авторы приходят к тому, что «цифровая экономика - это хозяйственная деятельность людей, особенностью которой является воздействие человека как субъекта производства не на предметы труда и средства труда, а на системы управления средствами труда» $[7$, c. 86]. Так в качестве основного критерия в приведенном определении служит выделение способа управления средствами труда за счет воздействия на них через специальные системы, функционирование которых обеспечивается благодаря цифровым технологиям, основанных на применении «больших» данных.

В работе В. В. Иванова и Г. Г. Малинецкого уделяется особое внимание развитию цифровой экономики в русле технологических укладов. В период с 2010-х годов осуществляется переход к VI технологическому укладу, сочетающему в себе новые отрасли и технологии, среди которых биотехнологии, новая медицина, робототехника, нанотехнологии, когнитивные технологии, высокие гуманитарные технологии, новое природопользование занимают особое место и, как подчеркивают упомянутые авторы, «все это в гораздо большей степени ориентировано на человека, чем технологические приоритеты предыдущего уклада» [8, с. 9]. «В современном понятии "цифровая экономика" речь идет об изменении технологической базы экономики, что позволит автоматизировать рутинные операции. Это значительно меняет скорость реализации многих процессов, предоставляет новые возможности, но не меняет базовых основ экономики» $[8$, с. 6$],-$ пишут названные авторы. В качестве одной из особенностей, характеризующих развитие технологий в настоящее время, служит их ориентированность на человека, выраженной, как описано В. В. Ивановым и Г. Г. Малинецким, в создании потребностей покупателей на товары, которые появятся на рынке, с чем мы согласны. «Однако сейчас происходит следующая бифуркация ключевое значение приобретают технологии, направленные не на производство и распределение товаров и услуг, а на самого человека. Если раньше компании работали для того, чтобы удовлетворить потребности и пожелания покупателей, то сейчас у них появилась возможность создать эти потребности, "заточить" покупателя под товар, который появится на рынке» [8, с. 15], - пишут названные авторы. Под точкой бифуркации понимается «переломный момент развития, когда будущее не определено» [9, с. 11], область бифуркации характеризуется «принципиальной непредсказуемостью». Как пишет С. Ю. Солодовников, в таких условиях невозможно определить заблаговременно, образуется ли «более упорядоченная структура или развитие системы станет хаотическим» [9, с. 11]. Формирование области бифуркации происходит за счет фллуктуаций, т. е. случайных отклонений «"мгновенных значений величин от их средних значений (от состояния равновесия)"» [9, с. 11], свидетельствующих о присутствии хаоса на микроуровне. Сильные флуктуации, приводящие к перестройке или гибели системы, становятся источником необратимости ее развития.

В цифровой экономике главное направление формирования потребностей, обусловленное стремлением каждого субъекта к поддержанию и максимизации своей жизненности и реализации жизненных сил, заменяется за счет манипулирования такими потребностями с помощью общественно-функциональных технологий, интересами производителей. П. С. Лемещенко по этому поводу фиксирует, что в настоящее время «основным средством приращения, возрастания капитала стали не производство и технологические инновации, а манипуляции сознанием практически всех слоев населения» $[10$, c. 51]. Основными особенностями цифрровой экономики являются, во-первых, значительное ускорение процессов воспроизводства, во-вторых, смена роли человека в ней. Место человека в цифровой экономике благодаря влиянию технологий оказывается в области бифуркации, дальнейшее развитие может сочетать как состояние прозрачности и управляемости отношений, так и состояние лишения человека возможности самостоятельного принятия решения.

Краткая характеристика описанных точек зрения на определение категории «цифровая экономика» наглядно представлена в таблице 1. 
Вестник Брестского государственного технического университета. 2021

Таблица 1 - Определение категории «цифровая экономика»

\begin{tabular}{|c|c|c|}
\hline \\
\hline+ & Содержание точки зрения & Преимущества точки зрения \\
\hline \multicolumn{3}{|c|}{ Воспроизводственно-цифровой подход } \\
\hline Г. Б. Клейнер & $\begin{array}{l}\text { цифровые технологии служат основой } \\
\text { воспроизводственного процесса, реальные } \\
\text { экономические модели, процессы, объекты, } \\
\text { проекты, среды дополняются и заменяются } \\
\text { виртуальными }\end{array}$ & $\begin{array}{l}\text { - выявлена информационно-технологическая основа } \\
\text { функционирования воспроизводственного механизма } \\
\text { в цифровой экономике, характеризующегося сближением } \\
\text { производства, распределения, обмена, потребления; } \\
\text { - определено, что обработка данных становится одним } \\
\text { из ключевых элементов развития воспроизводства за счет, } \\
\text { во-первых, точного прогнозирования его объемов } \\
\text { и структуры, во-вторых, влияния на процесс принятие } \\
\text { решения человеком }\end{array}$ \\
\hline А. Н. Козырев & $\begin{array}{l}\text { цифровая экономика как реальный сектор } \\
\text { экономики и как научное направление, } \\
\text { детерминированные процессом цифровизации, } \\
\text { свойствами информации в цифрровом формате } \\
\text { и ролью такой информации в экономике }\end{array}$ & $\begin{array}{l}\text { - выделены и охарактеризованы основные элементы } \\
\text { при рассмотрении реального сектора экономики и научного } \\
\text { направления: данные, инфоормация, знания в цифровом } \\
\text { формате, а также процесс их обработки; } \\
\text { - охарактеризованы свойства цифрового товара } \\
\text { и цифрового продукта, основанные на цифровом формате }\end{array}$ \\
\hline $\begin{array}{l}\text { В. В. Великороссов, } \\
\text { С. А. Филин } \\
\text { и О. Н. Калинина }\end{array}$ & $\begin{array}{l}\text { цифровая экономика как глобальная } \\
\text { система производства, распределения, обмена } \\
\text { и потребления, сформировавшаяся вследствие } \\
\text { мобилизации возможностей ИКТ }\end{array}$ & $\begin{array}{l}\text { - предложена структура цифровой экономики, состоящая } \\
\text { из трех подсистем (информационной, хозяйственной, } \\
\text { подсистемы отношений), позволяющая выявить наличие } \\
\text { в цифровой экономике разнобразных процессов, объединение } \\
\text { которых происходит благодаря цифровым ИКТ }\end{array}$ \\
\hline Р. Бухт и Р. Хикс & $\begin{array}{l}\text { цифровая экономика как составляющая часть } \\
\text { общего объема производства, сформированная } \\
\text { за счет цифровых технологий фирмами, бизнес- } \\
\text { модель которых основывается на цифровых } \\
\text { продуктах или услугах }\end{array}$ & $\begin{array}{l}\text { - подчеркивает расплывчатость границ в определении } \\
\text { цифровой экономики, одновременно позволяющая } \\
\text { учитывать скорость развития технологий; } \\
\text { - выделен перечень цифровых технологий: интернет- } \\
\text { технологии, «большие данные», облачные технологии }\end{array}$ \\
\hline \multicolumn{3}{|c|}{ Макро-детерминированный } \\
\hline Л. Сергеев & $\begin{array}{l}\text { цифровая экономика как область знаний } \\
\text { политической экономии, фокусирующая } \\
\text { в себе социальные и экономические стороны } \\
\text { общественного развития на сетевых } \\
\text { платформах и цифровых базах данных }\end{array}$ & $\begin{array}{l}\text { - сформулирована особенность, состоящая в ускорении } \\
\text { воспроизводства, в качестве факторов производства } \\
\text { выделены инфрормационные технологии и сетевые } \\
\text { платформмы; } \\
\text { - выделены политэкономические признаки, особенности } \\
\text { действия закона макроэкономического равновесия } \\
\text { за счет его «цифровой» основы }\end{array}$ \\
\hline \multicolumn{3}{|c|}{ Человеко-ориентированный } \\
\hline $\begin{array}{l}\text { Т. Н. Юдина } \\
\text { и И. З. Гелисханов }\end{array}$ & $\begin{array}{l}\text { цифровая экономика как экономика нового } \\
\text { технологического уклада, процессы которой } \\
\text { трансформируют производственные отношения, } \\
\text { их субъектно-объектную ориентированность } \\
\end{array}$ & $\begin{array}{l}\text { - обозначено изменение роли человека в социально- } \\
\text { экономических отношениях за счет интернетизации, } \\
\text { кибернетизации, выраженное в процессе создания } \\
\text { потребностей человека }\end{array}$ \\
\hline $\begin{array}{l}\text { Ю. В. Белоусов, } \\
\text { И. И. Тимофреева }\end{array}$ & $\begin{array}{l}\text { цифровая экономика как хозяйственная } \\
\text { деятельность людей, особенностью которой } \\
\text { является воздействие человека как субъекта } \\
\text { производства не на предметы труда и средства } \\
\text { труда, а на системы управления средствами труда }\end{array}$ & $\begin{array}{l}\text { - определено изменение способа взаимодействия } \\
\text { человека с предметами и средствами труда за счет } \\
\text { появления систем управления, основой которых служит } \\
\text { цифрровые технологий }\end{array}$ \\
\hline $\begin{array}{l}\text { В. В. Иванова и } \\
\text { Г. Г. Малинецкого }\end{array}$ & $\begin{array}{l}\text { цифровая экономика как экономика с прежними } \\
\text { базовыми основами и новой технологической } \\
\text { базой, воздействие которой направлено, } \\
\text { в первую очередь, на человека }\end{array}$ & $\begin{array}{l}\text { - выделена смена механизма формирования } \\
\text { потребностей, состоящая из процесса их создания } \\
\text { за счет цифровых технологий }\end{array}$ \\
\hline
\end{tabular}

Источник: разработка автора

\section{Заключение}

Благодаря исследованию А. Н. Козырева убеждаемся, что основу хозяйственного механизма цифровой экономики составляет информация в цифровом формате, свойства которой определяют особенности цифрровых продуктов и товаров. В цифровой экономике меняется механизм поиска информации, измерений, ведения переговоров, в результате чего снижаются трансакционные издержки по таким видам деятельности, тогда как отдельные издержки, связанные с неисполнением обязательств, наоборот возрастают. Структура цифровой экономики, предложенная В. В. Великороссовым, С. А. Филиным и О. Н. Калининой, состоит из трех подсистем - информационной, хозяйственной, подсистемы отношений - объединение которых происходит благодаря цифровым ИКТ. Взгляды Р. Бухта, Р. Хикса демонстрируют, что особенности, присущие производству в цифровой экономике определяются цифровыми технологиями, в качестве таких технологий названными авторами понимаются Интернет-технологии, мобильные и беспроводные сети, облачные технологии и технологии работы с большими данными. Т. Н. Юдина, И. З. Гелисханов, справедливо определяя цифровую экономику как экономику нового технологического уклада, фиксируют изменения природы и субъектно-объектной ориентированности производственных отношений за счет отношений типа машина-машина и сетевого механизма взаимодействия. На основании исследования Л. Сергеева видно, что цифровая экономика, понимаемая этим автором как область знаний политической экономии, сосредоточена на изучении социально-экономических механизмов и изменений, которые основаны на сетевых платформах и цифровых базах данных. Ключевые изменения воспроизводственного процесса проявляются, в первую очередь, в значительном его ускорении. В качестве факторов производства справедливо называются цифровые информационно-коммуникационные технологии и сетевые платформы. 
Цифровая экономика, ссормировавшаяся в условиях нового технологического уклада, характеризуется, прежде всего, трансформацией процессов производства, обмена, распределения и потребления, происходящих на основе сетевых механизмов взаимодействия, Интернета и инноваций. Цифровизация экономических и социальноэкономических процессов происходит благодаря масштабному применению компьютеров, технологий обработки и анализа данных, техники, направленной на присутствие в повседневной жизни человека. Происходящие изменения сопровождаются изменениями и в факторах производства, к которым в цифровой экономике относятся данные информация и знания. Предлагается в дальнейшем под цифровой экономикой понимать экономику, технически детерминированную применением цифровых технологий, функционирующих на основе «больших данных», которая характеризуется, во-первых, ускоренным воспроизводством, в том числе существенным сокращением затрат труда и времени на производство, во-вторых, усилением взаимосвязей и взаимозависимостей между социальной, экономической, политической, культурной сфрерами, в-третьих, присутствием манипуляционных общественно-функциональных технологий.

\section{Список цитированных источников}

1. Бухт, Р. Определение, концепция и измерение цифровой экономики / Р. Бухт, Р. Хикс // Вестник международных организаций. 2018. - T. 13. - № 2. - С. 143-172.

2. Клейнер, Г. Б. Интеллектуальная экономика цифрового века / Г. Б. Клейнер // Экономика и математические методы. - 2020. T. 56. - № 1. - С. 18-33.

3. Козырев, А. Н. Цифровая экономика и цифровизация в исторической перспективе / А. Н. Козырев // Цифровая экономика 2018. - № 1. - C. 5-19.

4. Великороссов, В. В. Цифровая экономика: терминологическая ретроспектива, современность и будущее / В. В. Великороссов, С. А. Филин, О. Н. Калинина // Экономический анализ: теория и практика / ООО «Издательский дом ФИНАНСЫ и КРЕДИТ». Москва, 2020. - Т. 19. - № 4 - С. 707-721.

5. Сергеев, Л. Экономическая природа содержательных положений цифровых платформ / Л. Сергеев // Общество и экономика. 2020. - № 3. - C. $45-63$.

6. Юдина, Т. Н. «Цифровая экономика» в зеркале и зазеркалье философии хозяйства и политической экономии [Электронный ресурс] / Т. Н. Юдина, И. 3. Гелисханов // Платформа научного обмена ReserchGate. - Режим доступа: https://www.researchgate.net/publication/341140683_Cifrovaa_ekonomika_v_zerkale_i_z azerkale_filosofii_hozajstva_i_politiceskoj_ekonomii. - Дата доступа: 24.09.2020.

7. Иванов, В. В. Цифровая экономика: мифы, реальность, возможности / В. В. Иванов, Г. Г. Малинецкий. - М. : Российская академия наук, 2017. -64 C.
8. Белоусов, Ю. В. Методология определения цифровой экономики / Ю. В. Белоусов, О. И. Тимофеева // Мир но-вой экономики. - 2019. № 13 (3). - C. 79-89. DOI: 10.26794/2220-6469-2019-13-4-79-89.

9. Солодовников, С. Ю. Понятие хаоса и его место в развитии сложных систем / С. Ю. Солодовников // Экономическая наука сегодня. - 2018. - № 7. - С 5-18.

10. Лемещенко, П. С. От стоимости к институциональной ценности / П. С. Лемещенко // Экономическая наука сегодня : сб. науч. ст. / БНТУ. - Минск, 2013. - Вып. 1. - С. 46-68. - С. 51.

\section{References}

1. Buht, R. Opredelenie, koncepciya i izmerenie cifrovoj ekonomiki / R. Buht, R. Hiks // Vestnik mezhdunarodnyh organizacij. - 2018. T. 13. - № 2. - S. 143-172.

2. Klejner, G. B. Intellektual'naya ekonomika cifrovogo veka / G. B. Klejner // Ekonomika i matematicheskie metody. - 2020. - T. 56. - № 1. S. 18-33.

3. Kozyrev, A. N. Cifrovaya ekonomika i cifrovizaciya v istoricheskoj perspektive / A. N. Kozyrev // Cifrovaya ekonomika - 2018. - № 1. S. $5-19$.

4. Velikorossov, V. V. Cifrovaya ekonomika: terminologicheskaya retrospektiva, sovremennost' i budushchee / V. V. Velikorossov, S. A. Filin, O. N. Kalinina // Ekonomicheskij analiz: teoriya i praktika / 000 «Izdatel'skij dom FINANSY i KREDIT». - Moskva, 2020. - T. 19. № 4 - S. 707-721.

5. Sergeev, L. Ekonomicheskaya priroda soderzhatel'nyh polozhenij cifrovyh platform / L. Sergeev // Obshchestvo i ekonomika. - 2020. № 3. - S. $45-63$.

6. Yudina, T. N. «Cifrovaya ekonomika» v zerkale i zazerkal'e filosofii hozyajstva i politicheskoj ekonomii [Elektronnyj resurs] / T. N. YUdina, I. Z. Geliskhanov // Platforma nauchnogo obmena ReserchGate. Rezhim dostupa: https://www.researchgate.net/publication/ 341140683_Cifrovaa_ekonomika_v_zerkale_i_zazerkale_filosofii_ho zajstva_i_politiceskoj_ekonomii. - Data dostupa: 24.09.2020.

7. Ivanov, V. V. Cifrovaya ekonomika: mify, real'nost', vozmozhnosti / V. V. Ivanov, G. G. Malineckij. - M. : Rossijskaya akademiya nauk, 2017. $-64 \mathrm{~s}$.

8. Belousov, Yu. V. Metodologiya opredeleniya cifrovoj ekonomiki / YU. V. Belousov, O. I. Timofeeva // Mir novoj ekonomiki. - 2019. № 13 (3). - S. 79 - 89. DOI: 10.26794/2220-6469-2019-13-4-79-89.

9. Solodovnikov, S. Yu. Ekonomika riskov / C. YU. Solodovnikov // Ekonomicheskaya nauka segodnya : sb. nauch. st. / BNTU. - Vyp. 8. 2018. - S. 16-55.

10. Lemeshchenko, P. S. Ot stoimosti k institucional'noj cennosti / P. S. Lemeshchenko // Ekonomicheskaya nauka segodnya : sb. nauch. st. / BNTU. - Minsk, 2013. - Vyp. 1. - S. 46-68. - S. 51.

Материал поступил в редакцию 20.10.2020 